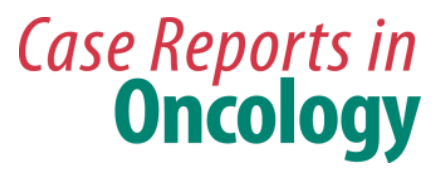

Case Rep Oncol 2017;10:462-472

DOI: $10.1159 / 000475806$

Publisned on Ine: IVlay 23, 2017
(C) 2017 The Author(s)

Published by S. Karger AG, Basel

www.karger.com/cro

This article is licensed under the Creative Commons Attribution-NonCommercial 4.0 International License (CC BY-NC) (http://www.karger.com/Services/OpenAccessLicense) Usage and distribution for commercial purposes requires written permission.

\title{
Systemic Therapy Outcomes in Adult Patients with Ewing Sarcoma Family of Tumors
}

\author{
Mario Valdes Garth Nicholas Shailendra Verma Timothy Asmis \\ Ottawa Hospital Research Institute, The Ottawa Hospital, University of Ottawa, \\ Ottawa, ON, Canada
}

\section{Keywords}

Ewing sarcoma - Bone cancer - Ewing sarcoma family of tumors - Peripheral primitive neuroectodermal tumor . Adult · Chemotherapy · Systemic therapy

\begin{abstract}
Background: The Ewing sarcoma family of tumors (ESFT) is a rare but curable bone neoplastic entity. The current standard of care involves chemotherapy and local disease control with surgery or radiation regardless of the extent of disease at presentation. Data that document the effectiveness of the current approach in the adult patient population are limited. Methods: We performed a retrospective review including all ESFT patients older than 19 years of age who received systemic therapy between January 2002 and December 2013 at our institution. The main study outcome was overall survival; secondary outcomes were objective response rate, disease-free survival, and progression-free survival. Results: Eighteen patients with ESFT were identified. The median overall survival for the entire group was 20.65 months (range $0.43-114.54$ ). In patients with localized disease, the 1-, 2-, and 3-year survival rates were 90,80, and 70\%, respectively. Age was not correlated with overall survival $(r=$ $0.58, p=0.76$ ). The 3 -year disease-free survival rate was $70 \%$. In patients with metastatic disease, the 1 -year survival rate was $40 \%$. In patients treated in the neoadjuvant and palliative setting with chemotherapy, we observed an objective response rate of $61.54 \%$. The time to progression in patients with metastatic disease treated with chemotherapy ranged from 0.69 to 4.93 months. Conclusion: In this group of adult patients with ESFT treated with mul-
\end{abstract}




\section{Case Reports in Oncology}

Valdes et al.: Systemic Therapy Outcomes in Adult Patients with Ewing Sarcoma Family of Tumors

timodality therapy, the outcomes were similar to those reported in well-known larger clinical trials that typically included younger patients. Age was not associated with worse survival.

(C) 2017 The Author(s)

Published by S. Karger AG, Basel

\section{Introduction}

The Ewing sarcoma family of tumors (ESFT) is a rare cancer entity. It is, however, the second most common primary malignancy originating from bone. Its peak incidence ranges from 10 to 15 years of age, and it is estimated that $30 \%$ of cases occur in adults over the age of 20 years [1,2]. It encompasses the histologic entities of Ewing sarcoma and peripheral primitive neuroectodermal tumor.

Before the use of multi-agent systemic therapy, the long-term survival rate of patients with Ewing sarcoma with surgery or radiation alone was less than $10 \%[3,4]$. With the addition of multidrug chemotherapy to surgery or radiation, 5-year survival rates now range from 37 to $60 \%$ in patients with metastatic disease and from 49 to $60 \%$ in patients with localized disease at presentation [5-13].

The current standard chemotherapy regimens are vincristine, doxorubicin, and cyclophosphamide alternating with ifosfamide and etoposide (VAC-I/E regimen) in localized disease, and vincristine, doxorubicin, and cyclophosphamide (VAC regimen) in metastatic disease [14-17].

As this is a rare cancer entity that affects mainly younger people, data documenting the effectiveness of the current standard chemotherapy regimens in adults are limited. We therefore sought to document the results observed at our institution with the use of these regimens in the adult population and review them in light of those presented in original practice-defining trials.

\section{Methods}

With institutional Research Ethics Board approval, we performed a retrospective review including all ESFT patients older than 19 years of age who had received systemic therapy between January 2002 and December 2013 at a tertiary academic cancer center which is the sole provider of medical oncology services to an urban and rural population of approximately 1.32 million people [18]. All patients were assigned a study number; no personal identifying information was used during data analysis.

We present the patient demographics, initial cancer stage, primary curative treatment provided, systemic therapy used, time to event outcomes, the different treatments on relapse, and responses to neoadjuvant or metastatic regimens. The main events we describe are relapse, progression, and death. The main study outcome was overall survival. Secondary outcomes were objective response rate, disease-free survival, and time to progression.

The objective response for each case was determined by reviewing the baseline and each follow-up clinical and radiology report performed during and immediately after each chemotherapy regimen, and it was reported using the RECIST criteria version 1.1. Overall 


\section{Case Reports in Oncology}

survival was measured from the date of diagnosis until the date of death or last follow-up. Disease-free survival was measured from completion of the primary treatment provided with curative intent until the date of confirmed relapse, death, or last follow-up. Progressionfree survival was measured in cases of metastatic disease at presentation, from the time of completion of the first line of systemic therapy until the time of confirmation of disease progression, death, or last follow-up.

We defined metastatic disease as stage IV disease on presentation according to the AJCC Cancer Staging Manual, ed 7, for soft tissue sarcomas. Performance status was presented as per the ECOG classification system.

Proportional data are presented in percentages, and measurements are described as medians and interquartile ranges. Pearson correlation with two-tailed significance was used to determine a direct or indirect relationship between two numerical variables.

\section{Results}

Twenty-two cases were identified through the hospital's health records system. Four were excluded because the main treatment was performed at another institution and therefore relevant information was not available (Fig. 1).

Table 1 shows the main characteristics of the 18 included cases at diagnosis. Their age ranged from 19 to 76 years, with a median of 38 years. Figure 2 shows the even distribution found across the age groups for both metastatic and localized disease. Ten patients had localized disease (55.56\%); 6 were women and 4 were men. A fusion gene was only reported in 2 cases with localized disease, and it was described as t(11:22). Eight patients presented with metastatic disease (44.44\%), i.e., 4 women and 4 men. Three cases of metastatic disease had a fusion gene reported; 1 was described as $\mathrm{t}(11: 22)$, the rest as EWSR1.

Fourteen cases (77.78\%) presented with an ECOG performance status of 0 or 1,10 with localized disease, and 4 with metastatic disease. All patients that were alive at their last documented hospital visit had a follow-up of at least 44 months from diagnosis. In 3 of these cases, follow-up was less than 60 months.

\section{Main Outcomes}

The main study events are represented in Figure 3. The median overall survival for the entire group was 20.65 months (range $0.43-114.54$ ). The overall survival rate at 3 years was $38.89 \%$ (7 of 18 cases). In patients with localized disease, the 1-, 2-, and 3-year survival rates were 90,80 , and $70 \%$, respectively; median overall survival was 47.41 months, and it ranged from 7.86 to 114.54 months. In patients with metastatic disease, the 1-year survival rate was 40\%; median overall survival was 9.55 months, and it ranged from 2.10 to 19.82 months.

Thirteen patients were treated with either neoadjuvant or palliative first-line systemic therapy. Their objective response rate was $61.54 \%$ (complete response: 0 patients; partial response: 8 patients). The stable disease rate was $15.38 \%$ (2 patients), and the progressive disease rate was $15.38 \%$ ( 2 patients). In 1 case, it was not possible to assess the response, due to incomplete records.

Ten patients underwent a primary intervention with curative intent (surgery in 7 cases, radiation in 3 cases); all had localized disease. Only 3 had their primary tumors in extremi- 


\section{Case Reports in Oncology}

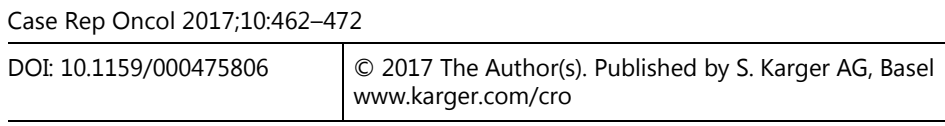

Valdes et al.: Systemic Therapy Outcomes in Adult Patients with Ewing Sarcoma Family of Tumors

ties. The rest had primaries in a maxillary sinus, the vertebral column, the thoracic wall, the bony pelvis, or the soft tissues of the abdomen or pelvis. The 3-year disease-free survival rate was $70 \%$ (7 cases). Median disease-free survival was 41.67 months (range 3.48114.54).

Four patients had metastatic disease at presentation and received systemic therapy; the time to progression ranged from 0.69 to 4.93 months.

\section{Management of Patients with Localized Disease}

Eight patients underwent 2-7 cycles of neoadjuvant chemotherapy, 5 with VAC-I/E, and 3 with VAC. Those on the VAC-I/E regimen received between 2.5 (2 full VAC-I/E cycles and 1 VAC cycle, without I/E) and 4 cycles. Five were able to achieve a partial response and 2 had stable disease, and in 1 case there was not enough information available to determine the best response. Two of these cases also received neoadjuvant radiation therapy. In one case, the tumor was located in the left leg and received 5,000 cGy before starting chemotherapy. In the other case, the tumor was located in the retroperitoneal area and received 4,500 cGy towards the end of neoadjuvant chemotherapy before undergoing resection via the anterior approach.

Five of the 8 patients who received neoadjuvant therapy actually underwent resection of the tumor. Three had tumors located in an extremity, and the rest had them in either a maxillary sinus, the axial skeleton, the thoracic wall, the soft tissues of the abdomen, or the soft tissues of the pelvis.

The 2 patients that did not receive neoadjuvant chemotherapy or radiotherapy underwent an initial surgical approach followed by adjuvant chemotherapy. One tumor was located in the soft tissues of the abdomen, and the other was an intradural tumor.

Four out of the 8 cases treated with neoadjuvant chemotherapy also received adjuvant chemotherapy. Two had achieved partial response with neoadjuvant chemotherapy, and 2 had stable disease.

\section{Radiation as Primary Therapy for Localized Disease}

In 3 cases, the primary therapy was radiation. In the first case, the tumor was located in the thoracolumbar spine, achieved partial response after 6 cycles of VAC, then received 4,500 cGy, and eventually relapsed locally after 18.3 months. In the second case, the tumor was located in the soft tissues of the thigh, achieved partial response after 2.5 cycles of VACI/E, then received 5,000 cGy, and relapsed distantly 6 months later. In the third case, the tumor was located in the thoracic wall, but was no longer visible on imaging after the initial biopsy. The patient received 2.5 cycles of neoadjuvant VAC-I/E followed by $6,000 \mathrm{cGy}$, and after 107.5 months, she did not have signs of relapse.

\section{Disease Recurrence}

Three patients recurred; 2 did so locally and 1 distally. The time to relapse was 11.37 , 15.45 , and 1.61 months, and overall survival was $32.94,21.47$, and 7.86 months, respectively. The 2 locally relapsed cases had vertebral column primaries. The patient with distant recurrence initially had a $14-\mathrm{cm}$ tumor in the soft tissues of the thigh. Seven patients did not have signs of disease recurrence after a median follow-up of 61.18 months (range 44.52114.54). 


\section{Case Reports in Oncology}

\begin{tabular}{l|l} 
Case Rep Oncol 2017;10:462-472 \\
\hline DOI: $10.1159 / 000475806$ & $\begin{array}{l}\text { C } 2017 \text { The Author(s). Published by S. Karger AG, Basel } \\
\text { www.karger.com/cro }\end{array}$
\end{tabular}

Valdes et al.: Systemic Therapy Outcomes in Adult Patients with Ewing Sarcoma Family of Tumors

\section{Management of Patients with Metastatic Disease}

None of the 8 patients with metastatic disease was able to undergo an intervention performed with curative intent. Four had primaries in the soft tissues of the abdomen or pelvis, 1 in the thoracic wall, 1 in the paraspinal soft tissues, and 1 in an extremity.

Five cases were treated with first-line systemic therapy. They all had an initial ECOG performance status of 1 . Two achieved partial response, and the rest achieved progressive disease (objective response rate $40 \%$ ). Primaries were located in the paraspinal soft tissues, long bones of the upper limb, pelvic bones, or soft tissues of the groin or pelvis. Time to progression in the group ranged from 0.69 to 4.93 months. In 1 case, data were not available.

Four patients went on to receive second-line systemic therapy, which consisted of I/E in 2 cases, gemcitabine and docetaxel in 1 case, and VAC in 1 case that had progressed after therapy in a clinical trial. Only the case that received VAC achieved partial response; all others had progressive disease (objective response rate $25 \%$ ).

Three patients underwent third-line chemotherapy, which, for each case, consisted of I/E, gemcitabine and docetaxel, and cisplatin and cyclophosphamide. In all of them, the best response was disease progression. Most of them required palliative radiation either concomitantly or sequentially to control the pain.

Two patients went on to receive a fourth line of chemotherapy. The best response was disease progression, and overall survival in these 2 patients was 13.55 and 19.82 months.

The overall survival in the 5 patients who received systemic therapy ranged from 5.72 to 19.82 months, with a median of 13.55 months.

Three patients did not receive any systemic therapy, due to a poor performance status. They were all treated with palliative radiation or medical symptom management.

\section{Discussion}

We described a group of patients with ESFT with predominantly soft-tissue, nonextremity primaries that spans from 19 to 76 years of age. All the patients with localized disease who received neoadjuvant chemotherapy were able to undergo either radical radiation therapy or surgery, and half of these cases went on to receive adjuvant chemotherapy. Most of the patients that underwent neoadjuvant and adjuvant chemotherapy received the VAC-I/E combination. A 3-year overall survival rate of 70\% in this group is congruent with that observed in the experimental group of the INT0091 trial [14] and in the retrospective review of ESFT in adults by Casey et al. [19] at the Memorial Sloan Kettering Cancer Center. Contrary to INT0091 and in agreement with Casey et al. [19], we did not observe a higher mortality with higher age. Even though in localized ESFT an initial tumor size of more than $8 \mathrm{~cm}$ is recognized as a strong prognostic factor for poor prognosis $[19,20]$, we did not observe this association in our small sample.

The presence and type of the fusion gene were largely underreported in our cohort, very likely because of the certainty of the diagnosis from histopathologic features and the lack of prognostic impact of the fusion transcript type noted in different trials, more relevantly in the large EE99 trial and recent North American studies [20].

Only 3 of our patients had ESFT that originated in the vertebral column or pelvis. Two had localized disease in the vertebral column, and 1 had metastatic disease with the primary 


\section{Case Reports in Oncology}

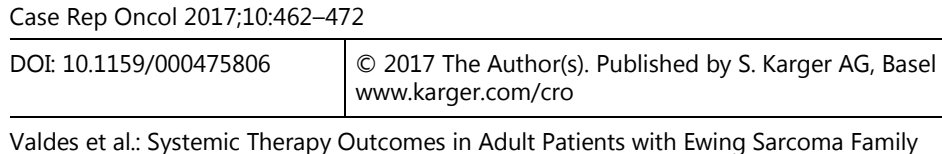
of Tumors

in the pelvic ring. They died at 13.38, 21.47, and 32.94 months (one-third of the patients alive at 2 years). In their retrospective review of 25 patients 15 years or older with ESFT originating in the axial skeleton (i.e., the vertebral column and pelvis), in which $20 \%$ had metastatic disease at presentation, Argon et al. [12] found a 2-year overall survival of $32.7 \%$. Localized pelvic primaries are known to portend a poorer prognosis [21]. Our sample may be limited, since we only found 1 case of this type.

Argon et al. [12] reported an objective response rate of $68 \%$ using the WHO response criteria. Across all primary sites, we observed an objective response rate of $61.54 \%$ using RECIST criteria version 1.1. Despite the different criteria used and the differences between the groups analyzed (axial skeleton vs. any primary location), the degree of response appears to be similar.

Metastatic status at diagnosis is the strongest prognostic factor [20]. We found this to be true in our cohort, where the metastatic disease group had a 1-year survival rate of $40 \%$ and where all patients were dead before 20 months of follow-up. In INT0091, the 1-year survival rate in this setting was approximately $60 \%$. This group of patients was not reviewed in detail in that study, hence comparisons to explain the difference in survival are not possible.

In this small group of adult patients with ESFT, we observed results similar to those reported in prospective clinical trials performed in younger patients. Our results argue against age being a determinant survival-prognostic factor.

\section{Statement of Ethics}

All procedures performed in this study were in accordance with the ethical standards of our institutional research committee and with the 1964 Declaration of Helsinki and its later amendments or comparable ethical standards. Ethics committee approval for the study was granted by the Ottawa Health Science Network Research Ethics Board. This paper does not contain individual or personal data on any participant.

\section{Disclosure Statement}

The authors declare that they have no competing interests.

\section{Funding Sources}

This original research was performed with the support of the University of Ottawa, The Ottawa Hospital, and the Ottawa Hospital Research Institute, Ottawa, ON, Canada. A source of external funding was not considered. 


\section{Authors' Contributions}

All the listed authors made a significant contribution to the conception, design, analysis, or interpretation of this original research. All authors read and approved the final manuscript.

\section{References}

1

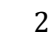

$>3$

Glass AG, Fraumeni JF Jr: Epidemiology of bone cancer in children. J Natl Cancer Inst 1970;44:187-199. Miller RW: Contrasting epidemiology of childhood osteosarcoma, Ewing's tumor, and rhabdomyosarcoma. Natl Cancer Inst Monogr 1981;56:9-15.

Iwamoto Y: Diagnosis and treatment of Ewing's sarcoma. Jpn J Clin Oncol 2007;37:79-89. Bernstein M, Heinrich K, Paulussen M, et al: Ewing sarcoma family of tumors: Ewing sarcoma of bone and soft tissue and the peripheral primitive neuroectodermal tumors; in Pizzo PA, Poplack DG (eds): Principles and Practice of Pediatric Oncology, ed 5. Philadelphia, Lippincott, Williams \& Wilkins, 2005, pp 1002-1032.

Sinkovics JG, Plager C, Ayala AG, Lindberg RD, Samuels ML: Ewing sarcoma: its course and treatment in 50 adult patients. Oncology 1980;37:114-119.

Siegel RD, Ryan LM, Antman KH: Adults with Ewing's sarcoma. An analysis of 16 patients at the DanaFarber Cancer Institute. Am J Clin Oncol 1988;11:614-617.

Baldini EH, Demetri GD, Fletcher CD, Foran J, Marcus KC, Singer S: Adults with Ewing's sarcoma/primitive neuroectodermal tumor: adverse effect of older age and primary extraosseous disease on outcome. Ann Surg 1999;230:79-86.

Klaassen R, Sastre-Garau X, Aurias A, Mosseri V, Palangié T, Laurent M, et al: Ewing's sarcoma of bone in adults: an anatomic-clinical study of 30 cases (in French). Bull Cancer 1992;79:161-167.

Martin RC 2nd, Brennan MF: Adult soft tissue Ewing sarcoma or primitive neuroectodermal tumors: predictors of survival? Arch Surg 2003;138:281-285.

Verrill MW, Judson IR, Harmer CL, Fisher C, Thomas JM, Wiltshaw E: Ewing's sarcoma and primitive neuroectodermal tumor in adults: are they different from Ewing's sarcoma and primitive neuroectodermal tumor in children? J Clin Oncol 1997;15:2611-2621.

Bacci G, Ferrari S, Comandone A, Zanone A, Ruggieri P, Longhi A, et al: Neoadjuvant chemotherapy for Ewing's sarcoma of bone in patients older than thirty-nine years. Acta Oncol 2000;39:111-116.

Argon A, Basaran M, Yaman F, Dizdar Y, Sakar B, Camlica H, et al: Ewing's sarcoma of the axial system in patients older than 15 years: dismal prognosis despite intensive multiagent chemotherapy and aggressive local treatment. Jpn J Clin Oncol 2004;34:667-672.

Fizazi K, Dohollou N, Blay JY, Guérin S, Le Cesne A, André F, et al: Ewing's family of tumors in adults: multivariate analysis of survival and long-term results of multimodality therapy in 182 patients. J Clin Oncol 1998;16:3736-3743.

Grier HE, Krailo MD, Tarbell NJ, Link MP, Fryer CJ, Pritchard DJ, et al: Addition of ifosfamide and etoposide to standard chemotherapy for Ewing's sarcoma and primitive neuroectodermal tumor of bone. N Engl J Med 2003;348:694-701.

Ahmed SK, Robinson SI, Okuno SH, Rose PS, Laack NN: Adult Ewing sarcoma: survival and local control outcomes in 102 patients with localized disease. Sarcoma 2013;2013:681425.

Miser JS, Krailo MD, Tarbell NJ, Link MP, Fryer CJ, Pritchard DJ, et al: Treatment of metastatic Ewing's sarcoma or primitive neuroectodermal tumor of bone: evaluation of combination ifosfamide and etoposide - a Children's Cancer Group and Pediatric Oncology Group study. J Clin Oncol 2004;22:28732876.

Kolb EA, Kushner BH, Gorlick R, Laverdiere C, Healey JH, LaQuaglia MP, et al: Long-term event-free survival after intensive chemotherapy for Ewing's family of tumors in children and young adults. J Clin Oncol 2003;21:3423-3430.

Ontario Local Health Integration Networks: Environmental Scan: 2016-2019 Integrated Health Services Plans. Prepared by the Health Analytics Branch of Ministry of Health and Long-Term Care. 2015. http://www.champlainlhin.on.ca/ /media/sites/champlain/About\%20Us/GeoPopHlth/201619\%20Envrmntl\%20Scan\%20Jul2015.pdf?la=en (accessed December 1, 2015). 


\section{Case Reports in Oncology}

19 Casey DL, Meyers PA, Alektiar KM, Magnan H, Healey JH, Boland PJ, et al: Ewing sarcoma in adults treated with modern radiotherapy techniques. Radiother Oncol 2014;113:248-253.

20 Gaspar N, Hawkins DS, Dirksen U, Lewis IJ, Ferrari S, Le Deley MC, et al: Ewing sarcoma: current management and future approaches through collaboration. J Clin Oncol 2015;33:3036-3046.

21 Karosas AO: Ewing's sarcoma. Am J Health Syst Pharm 2010;67:1599-1605.

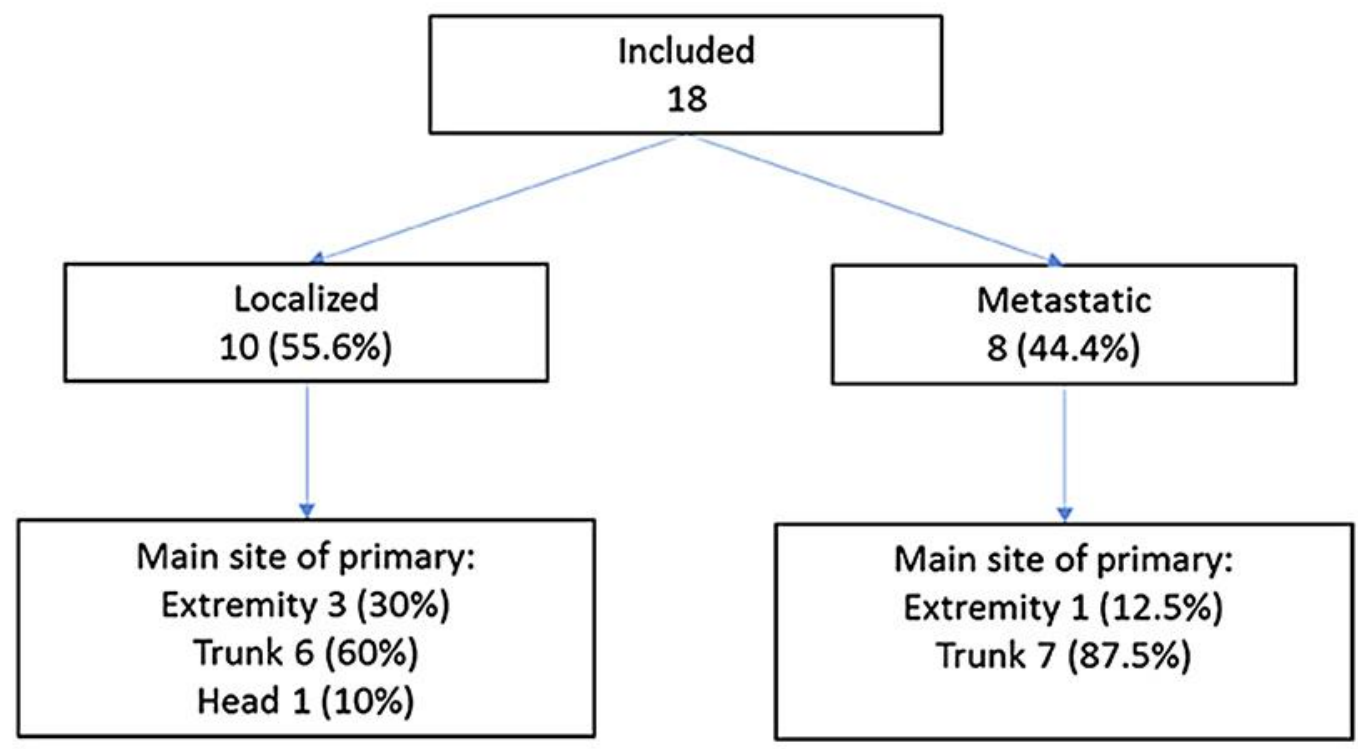

Fig. 1. Flow diagram of patient inclusion. 


\section{Case Reports in Oncology}

\begin{tabular}{l|l}
\hline DOI: $10.1159 / 000475806$ & (c 2017 The Author(s). Published by S. Karger AG, Basel
\end{tabular} www.karger.com/cro

Valdes et al.: Systemic Therapy Outcomes in Adult Patients with Ewing Sarcoma Family of Tumors

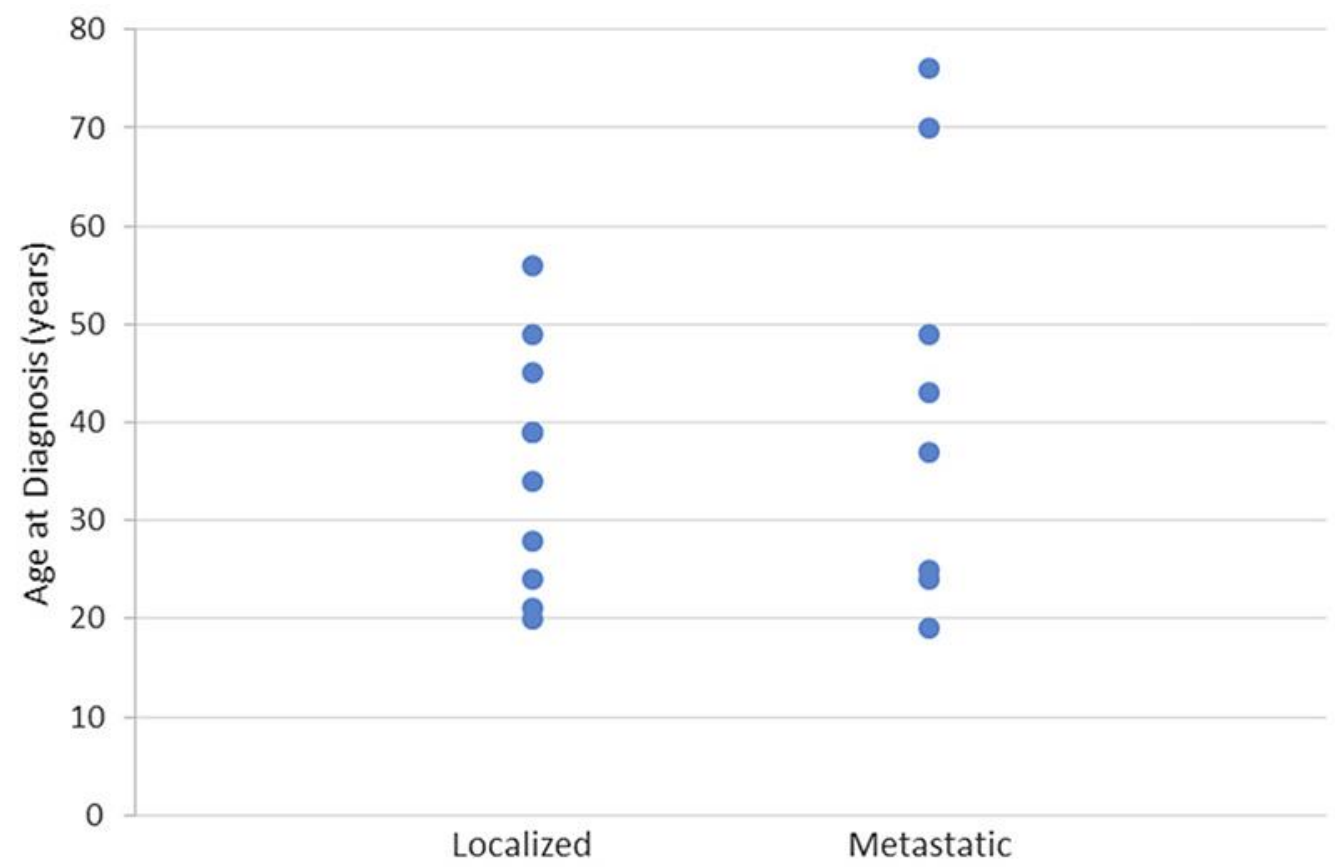

Fig. 2. Distribution of disease presentation according to age at diagnosis. 


\section{Case Reports in Oncology}

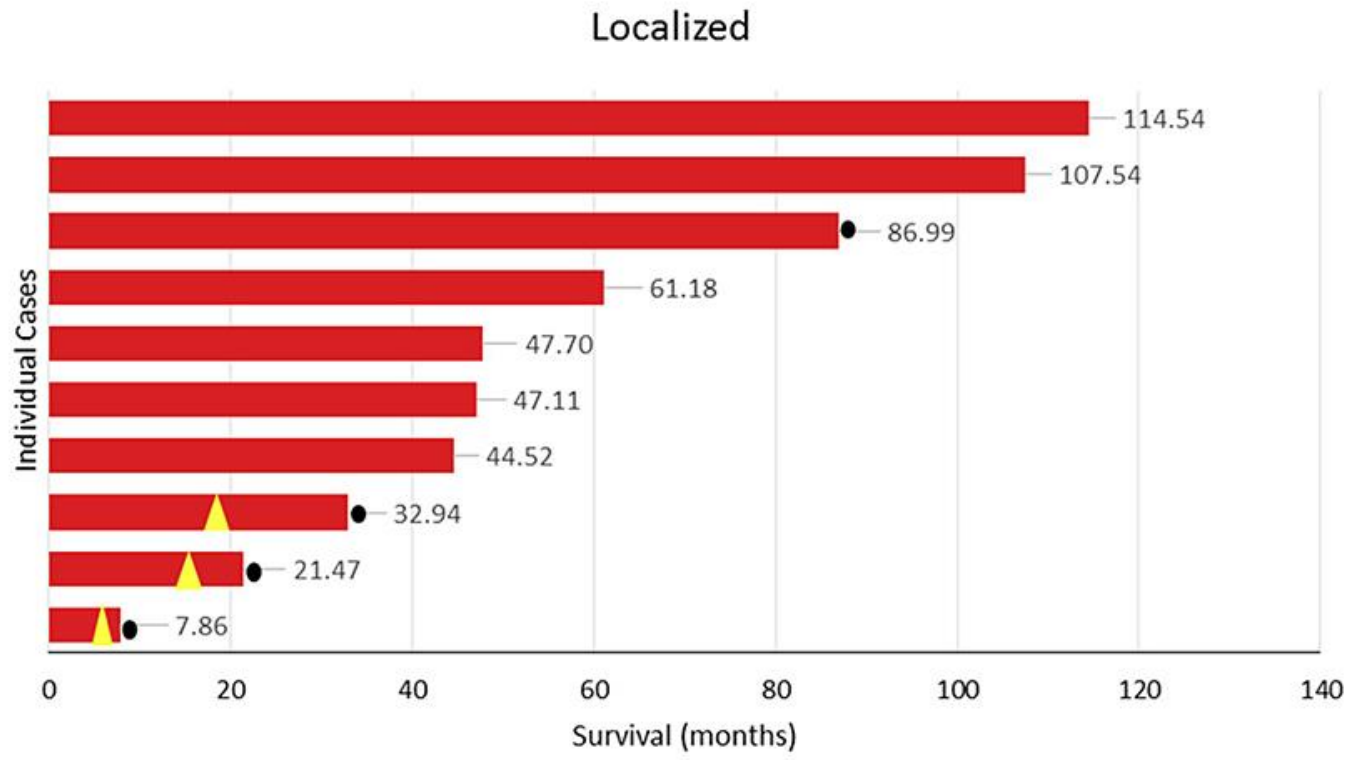

\section{Metastatic}

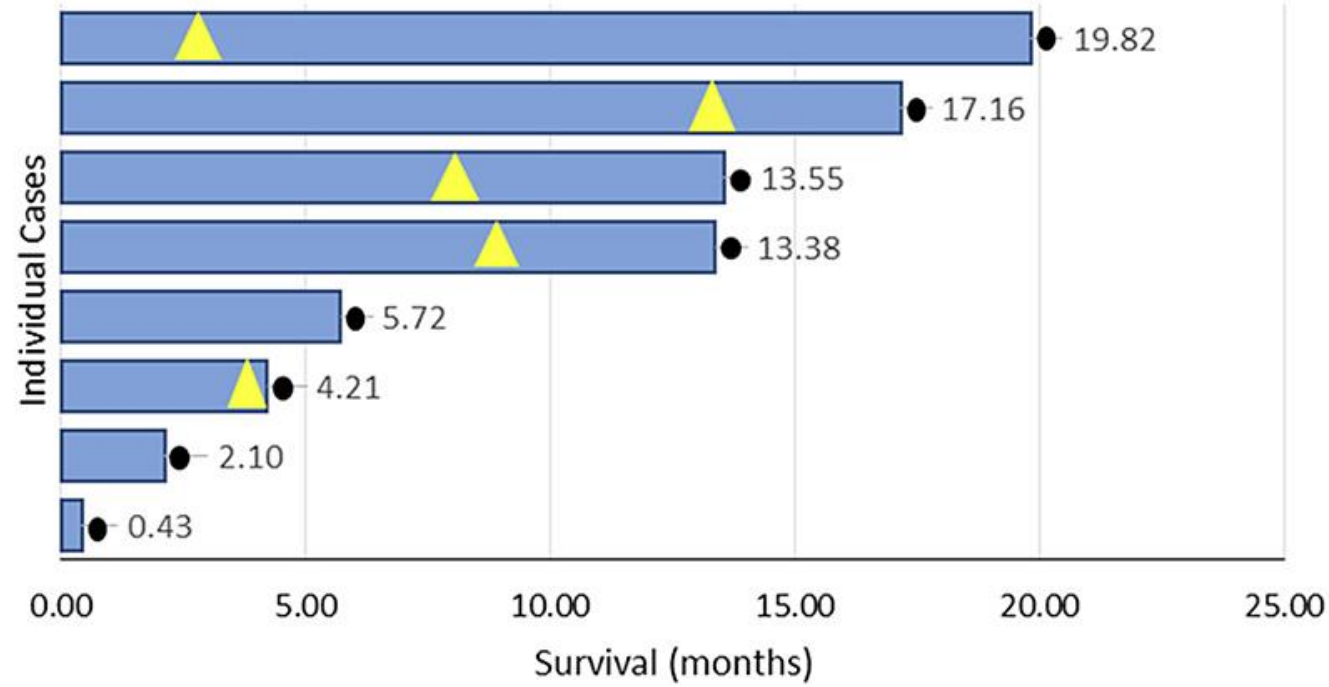

Fig. 3. Overall survival by extent of disease at presentation. Yellow triangles signal time of relapse; black dots signal death. 


\section{Case Reports in Oncology}

\begin{tabular}{l|l} 
DOI: $10.1159 / 000475806$ & (C) 2017 The Author(s). Published by S. Karger AG, Basel
\end{tabular} www.karger.com/cro

Valdes et al.: Systemic Therapy Outcomes in Adult Patients with Ewing Sarcoma Family of Tumors

Table 1. Baseline characteristics

\begin{tabular}{|c|c|c|c|}
\hline & Localized & Metastatic & Both \\
\hline Median age (range), years & $36.5(20-56)$ & $40(19-76)$ & $38(19-76)$ \\
\hline \multicolumn{4}{|l|}{ Gender, $n$} \\
\hline Female & 6 & 4 & 10 \\
\hline Male & 4 & 4 & 8 \\
\hline \multicolumn{4}{|l|}{ Performance status, $n$} \\
\hline $0-1$ & 10 & 4 & 14 \\
\hline 2 or higher & 0 & 3 & 3 \\
\hline Not available & 0 & 1 & 1 \\
\hline \multicolumn{4}{|l|}{ Stage, $n$} \\
\hline I & 0 & 0 & 0 \\
\hline II & 9 & 0 & 9 \\
\hline III & 0 & 0 & 0 \\
\hline IV & 0 & 8 & 8 \\
\hline Not available & 1 & 0 & 1 \\
\hline \multicolumn{4}{|l|}{ Tissue of origin, $n$} \\
\hline Osseous & 5 & 3 & 8 \\
\hline Nonosseous & 5 & 5 & 10 \\
\hline \multicolumn{4}{|l|}{ Site of primary, $n$} \\
\hline Vertebral column & 2 & 0 & 2 \\
\hline Pelvic ring & 0 & 1 & 1 \\
\hline Maxillary sinus & 1 & 0 & 1 \\
\hline Thoracic wall & 1 & 1 & 2 \\
\hline Abdominal wall & 1 & 0 & 1 \\
\hline Paraspinal soft tissues & 0 & 1 & 1 \\
\hline Gluteal, groin, pelvic soft tissues & 1 & 3 & 4 \\
\hline Peritoneum/retroperitoneum & 1 & 1 & 2 \\
\hline Extremities & 3 & 1 & 4 \\
\hline Total & 10 & 8 & 18 \\
\hline
\end{tabular}

